OPEN ACCESS

Edited by:

Sergio Olate,

University of La Frontera, Chile

Reviewed by:

Furkan Erol Karabekmez, University of Health Sciences, Turkey

Fatih Zor,

Wake Forest School of Medicine, United States

*Correspondence: Sam P. Tarassoli

sam.tarassoli@outlook.com

Specialty section

This article was submitted to Reconstructive and Plastic Surgery,

a section of the journal

Frontiers in Surgery

Received: 24 February 2020

Accepted: 19 October 2020

Published: 07 December 2020

Citation:

Tarassoli SP, Shield ME, Allen RS,

Jessop ZM, Dobbs TD and

Whitaker IS (2020) Facial

Reconstruction: A Systematic Review

of Current Image Acquisition and

Processing Techniques.

Front. Surg. 7:537616.

doi: 10.3389/fsurg.2020.537616

\section{Facial Reconstruction: A Systematic Review of Current Image Acquisition and Processing Techniques}

\author{
Sam P. Tarassoli ${ }^{1,2 *}$, Matthew E. Shield ${ }^{3}$, Rhian S. Allen ${ }^{2}$, Zita M. Jessop ${ }^{1,2}$, \\ Thomas D. Dobbs ${ }^{1,2}$ and lain S. Whitaker ${ }^{1,2}$ \\ ${ }^{1}$ Reconstructive Surgery \& Regenerative Medicine Research Group, Swansea University Medical School, Swansea, \\ United Kingdom, ${ }^{2}$ Welsh Centre for Burns and Plastic Surgery, Morriston Hospital, Swansea, United Kingdom, ${ }^{3}$ College of \\ Medicine, Swansea University Medical School, Swansea, United Kingdom
}

Introduction: Plastic and reconstructive surgery is based on a culmination of technological advances, diverse techniques, creative adaptations and strategic planning. $3 \mathrm{D}$ imaging is a modality that encompasses several of these criteria while encouraging the others. Imaging techniques used in facial imaging come in many different modalities and sub-modalities which is imperative for such a complex area of the body; there is a clear clinical need for hyper-specialized practice. However, with this complexity comes variability and thus there will always be an element of bias in the choices made for imaging techniques.

Aims and Objectives: The aim of this review is to systematically analyse the imaging techniques used in facial reconstruction and produce a comprehensive summary and comparison of imaging techniques currently available, including both traditional and novel methods.

Methods: The systematic search was performed on EMBASE, PubMed, Scopus, Web of Science and Cochrane reviews using keywords such as "image technique/acquisition/processing," "3-Dimensional," "Facial," and "Reconstruction." The PRISMA guidelines were used to carry out the systematic review. Studies were then subsequently collected and collated; followed by a screening and exclusion process with a final full-text review for further clarification in regard to the selection criteria. A risk of bias assessment was also carried out on each study systematically using the respective tool in relation to the study in question.

Results: From the initial 6,147 studies, 75 were deemed to fulfill all selection criteria and selected for meta-analysis. The majority of papers involved the use of computer tomography, though the use of magnetic resonance and handheld scanners using sonography have become more common in the field. The studies ranged in patient population, clinical indication. Seminal papers were highlighted within the group of papers for further analysis.

Conclusions: There are clearly many factors that affect the choice of image acquisition techniques and their potential at being ideal for a given role. Ultimately the surgical team's choice will guide much of the decision, but it is crucial to be aware of not just the diagnostic ability of such modalities, but their treatment possibilities as well.

Keywords: reconstruction, facial 3D images, image acquisition, imaging technique, 3D printing 


\section{INTRODUCTION}

The advancement of modern imaging techniques in plastic and reconstructive surgery has led to ever improving patient outcomes, allowing the surgeon to visualize and gain a better spatial appreciation during complex surgical procedures. Of those utilized, three-dimensional (3D) imaging has become commonplace due to its accuracy, precision, and versatility (1). 3D imaging has multiple modalities, each with their own advantages and disadvantages; these include, but are not limited to, magnetic resonance imaging (MRI), computed tomography (CT), 3D photography and handheld scanners using sonography (Table 1). All these modalities and their respective sub-modalities play their own role in the diagnosis, planning, and treatment of the patient, thereby, becoming a cornerstone of preoperative, perioperative, and postoperative care (2). In facial reconstructive surgery, the use of detailed facial imaging techniques is imperative for such an anatomically intricate area of the body; for this reason, there is a clear clinical need for hyperspecialized practice (3).

The advancement of facial reconstructive surgery has coincided with the evolution of the imaging modalities available for patient assessment, surgical planning, and postoperative follow-up. For decades, prior to the development of CT and MRI in the late 1970s, clinical 2D photography was utilized as the primary imaging modality for the objective measure of surgical outcomes (4). The use of $2 \mathrm{D}$ clinical photography continues to be a cornerstone of plastic surgery due to its availability, ease of obtainment, and reproducibility when re-examination is required (5).

The introduction of CT and MRI scans in the early 1980s as well as recent advancements in 3D photography and ultrasound scanners permit detailed geometric, topographical, and volumetric analysis, allowing the surgeon to form a more accurate clinical picture for preoperative surgical planning and/or intraoperative surgical guidance (6). Advancements in imaging modalities and increasing literature in this field necessitates a comprehensive review of the advantages and disadvantages of each imaging technique to act as a guide for clinicians involved in facial reconstruction. In addition to the high resolution of these imaging modalities, the ability to combine these with angiography components adds an extra and indispensable element to the preoperative planning process $(7,8)$.

With the variety of imaging techniques and computer processing systems available, identifying which case-specific imaging modality to use has become a challenge, with each modality having a situational-dependent advantage. The importance of an evidence-based imaging choice cannot be overstated when picking a modality; it becomes easy for bias to be formed through familiarity rather than best practice. Despite this, there is limited literature available that strives to provide conclusions and therefore limited guidance for surgeons on which imaging modality to utilize for specific facial reconstructive procedures.

Surgical planning is a broad term that encompasses several meanings; here, it refers specifically to the use of image acquisition and processing techniques used in the context of
TABLE 1 | Summary table highlighting the advantages and disadvantages of various imaging techniques.

\begin{tabular}{|c|c|c|}
\hline $\begin{array}{l}\text { Imaging } \\
\text { technique }\end{array}$ & Advantages & Disadvantages \\
\hline CT & $\begin{array}{l}\text { - Provide detailed picture } \\
\text { with tissue differentiation } \\
\text { of both hard and soft } \\
\text { tissues } \\
\text { - Shows acute bleeds } \\
\text { - Painless and noninvasive } \\
\text { - Angiographic capabilities } \\
\text { for specific } \\
\text { preoperative planning }\end{array}$ & $\begin{array}{l}\text { - } \text { Time consuming } \\
\text { - Expensive (less than MRI) } \\
\text { - Skilled technicians } \\
\text { required } \\
\text { - lonizing radiation dose } \\
\text { - Contrast materials may } \\
\text { be required that can } \\
\text { be harmful }\end{array}$ \\
\hline MRI & $\begin{array}{l}\text { - Provides a detailed } \\
\text { picture of soft tissues } \\
\text { structures more } \\
\text { accurately than CT } \\
\text { - No ionizing radiation dose } \\
\text { - Painless and noninvasive } \\
\text { - Contrast materials used } \\
\text { are not as harmful } \\
\text { - Angiographic capabilities } \\
\text { for specific } \\
\text { preoperative planning }\end{array}$ & $\begin{array}{l}\text { - Time consuming } \\
\text { - Expensive } \\
\text { - Skilled } \\
\text { required } \\
\text { - Not usable for patients } \\
\text { with older surgical metals } \\
\text { in body } \\
\text { - Implantable medical } \\
\text { devices may malfunction } \\
\text { during use } \\
\text { (i.e., pacemakers) }\end{array}$ \\
\hline $\begin{array}{l}\text { Handheld } \\
\text { sonography } \\
\text { scanners }\end{array}$ & $\begin{array}{l}\text { - Portable, lightweight, and } \\
\text { mobile-can be } \\
\text { performed at the bedside } \\
\text { - Quick and inexpensive } \\
\text { - Adjunct to the } \\
\text { clinical examination }\end{array}$ & $\begin{array}{l}\text { - Lower resolution and } \\
\text { image quality } \\
\text { - Can be limited to 2D } \\
\text { - Small screen size makes } \\
\text { visualization difficult }\end{array}$ \\
\hline 2D photography & $\begin{array}{l}\text { - Specialist training not } \\
\text { required } \\
\text { - Inexpensive } \\
\text { - Easy and efficient } \\
\text { downstream processing } \\
\text { - Easily reproducible }\end{array}$ & $\begin{array}{l}\text { - Does not provide } \\
\text { detailed topographical } \\
\text { measurements } \\
\text { - Provides no } \\
\text { subsurface imaging }\end{array}$ \\
\hline 3D photography & $\begin{array}{l}\text { - Provides detailed } \\
\text { topographical } \\
\text { measurements of the face } \\
\text { - Relatively inexpensive } \\
\text { - Easily reproducible }\end{array}$ & $\begin{array}{l}\text { - Specialist training required } \\
\text { - Ease of availability }\end{array}$ \\
\hline
\end{tabular}

facial reconstructive plastic surgery. The aim of surgical planning is to simply acquire the most comprehensive representation of the structure being operating on, thus, visualizing the surgery about to be undertaken. This visualization can be done with single or multiple imaging techniques, often multimodal approaches providing the most comprehensive picture. Surgical planning begins with image capture of the specific anatomical area, these images are then rendered using modality-dependent processing techniques (9). The result of this is a virtual 3D model that allows for visualization of the anatomy from different angles and provides the surgeon with a "mental map" that allows for surgical navigation throughout the operation (10). With these tools at their fingertips, a clear stepwise approach can be taken for each operation. In addition to this, these walkthroughs can be shown to patients to allow education and inform the consent process and therefore improve patient outcomes (11). 
The aim of this systematic review was to highlight all the available image acquisition and processing techniques that have been utilized for bony facial reconstruction in the literature. The goal is that this forms a comprehensive summary of the available bony facial imaging techniques for surgeons involved in facial reconstruction and guides decision making based on patient-specific needs.

\section{METHODS}

\section{Search Strategy}

A systematic review protocol was developed in accordance with the recommendations of the Preferred Reporting Items for Systematic Reviews and Meta-Analyses (PRISMA) guidelines (Figure 1) (12) to evaluate the types of imaging techniques and their clinical variability in the literature To identify all relevant papers, a comprehensive search strategy was developed and pretested, with an example of the search strategy used; the full search having being provided later in the Methods section. Searches were performed in Web of Science (Web of Science Core Collection, BIOSIS Citation index, KCI-Korean Journal Database, MEDLINE, SciELO Citation Index), PubMed, Scopus, OVID, and Embase. The review was additionally registered on the International prospective register of systematic reviews (PROSPERO) (13).

The specific search and selection strategy performed is highlighted below and is based on the initial search strategy registered with PROSPERO. The keywords and strategy utilized is as follows;

"((facial OR maxillofacial) AND (reconstruction OR recon surgery)) AND ((image technique) OR (image acquisition) OR (image processing) OR ((computed tomography) OR (magnetic resonance imaging) $O R$ (ultrasonography) $O R$ $(3 D$ photography) )))"

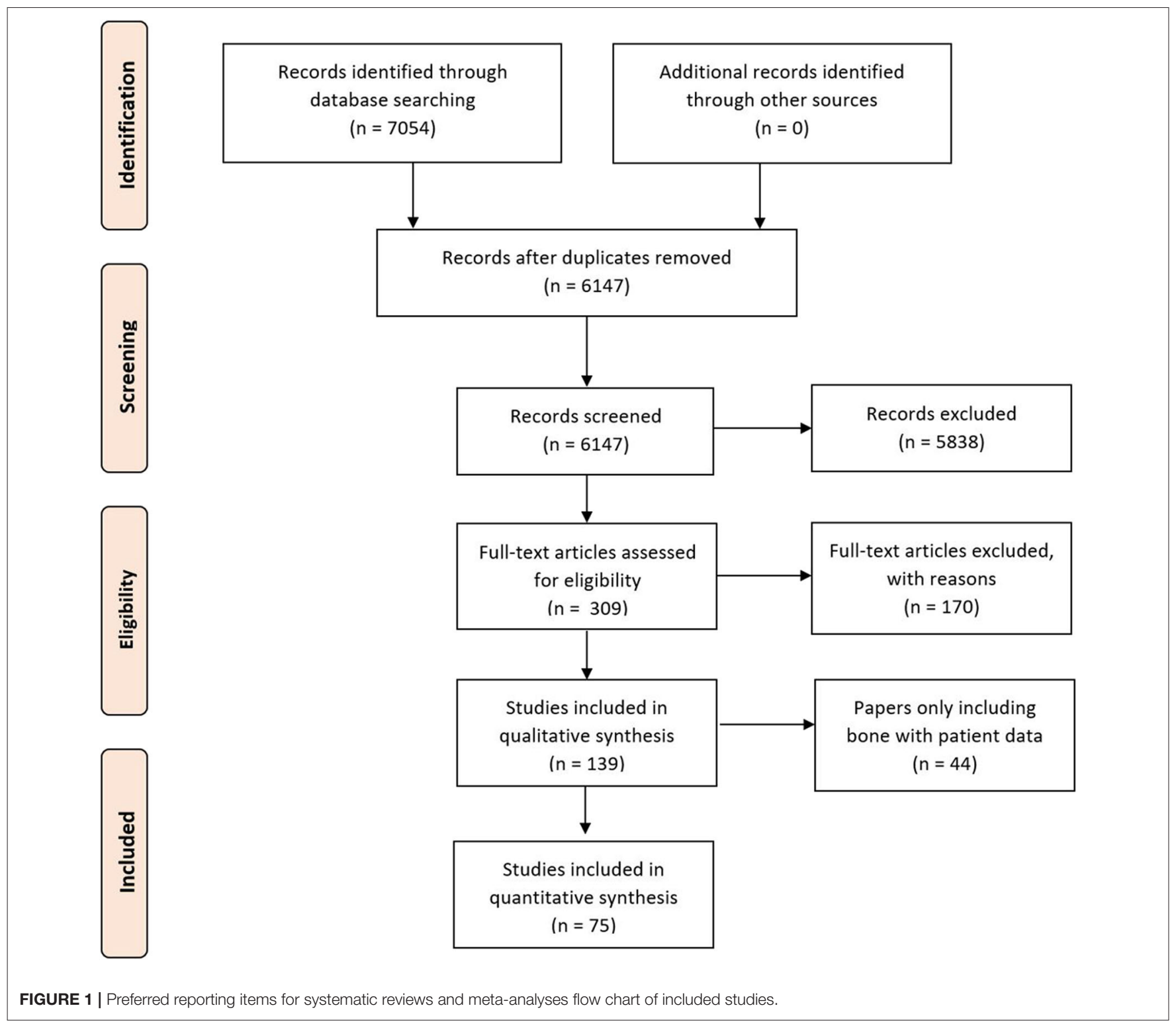


This search strategy provided a clear but precise identification of relevant articles in the literature. These papers were then screened further by the use of specific eligibility and exclusion criteria.

\section{Eligibility Criteria}

Eligibility for article inclusion were (1) all studies included involved facial imaging techniques; (2) bone reconstruction; (3) included only imaging modalities aiming to visualize bony structures or imaging modalities aiming to visualize facial reconstruction; (4) clinical patient outcomes; (5) English language articles only.

\section{Exclusion Criteria}

Studies were excluded if they met the following criteria: (1) no clinical component; (2) involved non-facial surgical techniques; (3) purely soft tissue reconstruction; (4) contained no surgical component; (5) were not available for viewing. Review articles and commentaries were also excluded.

\section{Study Selection}

Two reviewers (S. P. T. and M. E. S.) independently reviewed the studies with differences resolved by a third reviewer (R. S. A.). Titles were initially screened to exclude duplicates and further screened using the abstracts against inclusion and exclusion criteria. Finally, full text review of the remaining articles was performed to assess for eligibility.

\section{Data Extraction and Main Outcomes}

Data were extracted from the selected studies using a standardized format (Microsoft Office Excel 2019). The initial tabulated data collection included: anatomy, patient demographic, study demographic, methodology, study design, primary and secondary outcomes, complications, and clinical availability.

\section{Risk-of-Bias Assessment}

Studies were examined for bias using the Cochrane tool (RoB 2.0) (14) as a guide alongside modified versions of the tool and evaluations of the tool itself (15). The literature was separated into cohort-based (Table 2) and trial-based (Table 3) categories due to the differing criteria needed for assessing the bias (16).

\section{RESULTS}

The initial study numbers that were found (after duplicate removal) were 6,147, which led to the final inclusion of 75 . Papers were removed from the screening and data extraction stage if they did not abide by the criteria laid out in the PROSPERO protocol. The papers were categorized into the anatomical area of the face that the work correlated to and then arranged by the date of publication (Table 4).

The frequency of the studies was looked at depending on the year of publication (Figure 2) and it was found that there was an almost exponential rise after 2011 which would be explained by the readiness of the technology available and the emergence of $3 \mathrm{~d}$ printing abilities.
Risk-of-bias assessments were carried out using different tools that depended upon the type of study that was being assessed, i.e., cohort vs. trial-based study.

\section{DISCUSSION}

As can be seen from the analysis and results collation, there are many varying papers in the literature that use facial imaging in the clinical environment. Whether for diagnosis, treatment or prognosis, these techniques are commonplace in surgical theaters throughout the world and will become even more so in the future. It becomes a difficult task to analyze all the studies in a quantifiable sense due to the sheer variability between them, but it would be prudent to highlight what could be seminal papers in the field so that they can be turned to as reference. Not only are the key points of the papers crucial, but the impact factor of the journal and the ideals that they hope to achieve in future studies.

The seminal papers for the imaging modalities discussed have been selected through multiple means following a rigorous search strategy and certain criteria. These include but are not limited to: the papers impact factor, cohort study size, study type and low bias. The seminality of the papers selected has been based on the authors being the first to report specific imaging modality technique or being the first to utilize it in clinical practice with reportable and significant current and or future clinical impact.

The limitations of the search and the analysis of data should be noted. With such a large volume of papers to analyze there will be certain branches of facial surgery that were excluded. The foremost being orthognathic surgery. It was considered to include this in the search and analysis of papers, but it was decided that due to the complexity and the vastness of the topic (as it stetches into the world of maxillofacial and dental medicine) to not include these papers. Though one cannot argue the benefit for including these papers in the global scheme of analysis of facial imaging techniques, but with the search that was used, this would not be thorough or robust enough to include the seminal orthognathic papers (87). Similar to this, the use of alloplastic materials are a potential limitation of the review and search strategy. Though the systematic review did not intend to specifically mention imaging of alloplastic implants, we are aware of this challenge and the clinical benefit of the techniques used (88). However, further research would be needed to explicitly look at these criteria. Another limitation of this study is that though a comparable analysis of papers was attempted to be made with data extraction, due to the heterogeneity of the data and the techniques themselves, a true meta-analysis could not be carried out. However, the variability of clinical cases shows that perhaps a meta-analysis would not be of great benefit as it will not provide data that would be translatable to practice.

A detailed and comprehensive research strategy allowed for the exclusion of many papers. Where impact factor was low or cohort size restricted to minimal patients, there was a greater likelihood of exclusion. Although, it should be noted that low impact factor or cohort size did not guarantee exclusion if, in fact, 
TABLE 2 | Risk-of-bias asssessment on cohort studies.

\begin{tabular}{|c|c|c|c|c|c|c|c|c|c|}
\hline References & Study design & Confounding & $\begin{array}{l}\text { Selection of } \\
\text { participants }\end{array}$ & $\begin{array}{l}\text { Measurement } \\
\text { of } \\
\text { interventions }\end{array}$ & $\begin{array}{l}\text { Departures } \\
\text { from } \\
\text { intended } \\
\text { interventions }\end{array}$ & $\begin{array}{l}\text { Missing } \\
\text { data }\end{array}$ & $\begin{array}{l}\text { Measurement } \\
\text { of outcomes }\end{array}$ & $\begin{array}{l}\text { Selection of } \\
\text { reported } \\
\text { results }\end{array}$ & $\begin{array}{l}\text { Overall risk } \\
\text { of bias }\end{array}$ \\
\hline
\end{tabular}

An et al. (82)

Not stated

Andrews et al. (31) Multicenter retrospective

Broumand et al. (22)

Not stated

Davies et al. (55)

Retrospective

Dong et al. (73)

Eppley (24)

cross-sectional

Farook et al. (84)

Retrospective

Clinical series

Frellesen et al. (63)

Fu et al. (51)

Gander et al. (69)

Gerbino et al. (28)

Not stated

Retrospective

Retrospective

Retrospective

Case series

Gibelli et al. (70)

Not stated

Guest et al. (86)

Single-center

case series

Gui et al. (27)

Guo et al. (21)

Heiland et al. (74)

Not stated

Not stated

Not stated

Heissler et al. (17)

Not stated

Kim et al. (72)

Not stated

Klenk and Kovacs (25) Retrospective

Kokosis et al. (85)

Retrospective

Kraeima et al. (54)

Not stated

Kwon et al. (64)

Not stated

Not stated

Lim et al. (80)

Not stated

Mascha et al. (52)

Retrospective

Myga-Porosito et al.

Not stated

(79)

Novelli et al. (65)

Not stated

Ohkawa et al. (58)

Not stated

Rabie et al. (26)

Preliminary

series

Reiser et al. (57)

Not stated

Sawh-Martinez et al. Not stated

(53)

Schmutz et al. (29)

Cross sectional

Shaye et al. (60)

Sozzi et al. (71)

Suzuki et al. (40)

Retrospective

review

Retrospective

Not stated

Suzuki-Okamura et al. Not stated

(32)

Tabakovic et al. (67)

Taoet al. (59)

Not stated

Not stated

Tarsitano et al. (68)

Tarsitano et al. (61)

Tel et al. (36)

Not stated

Not stated

Not stated

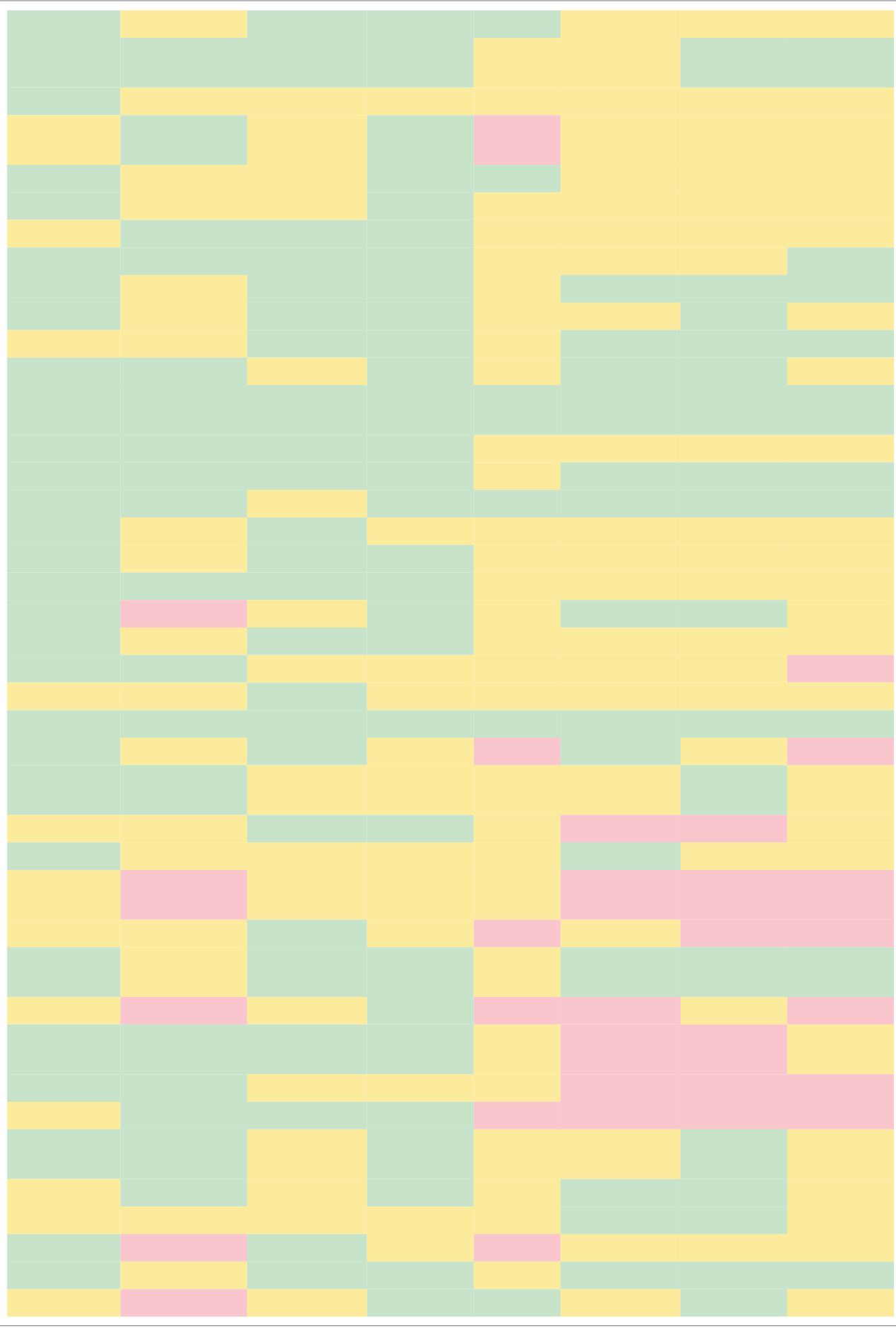

(Continued) 
TABLE 2 | Continued

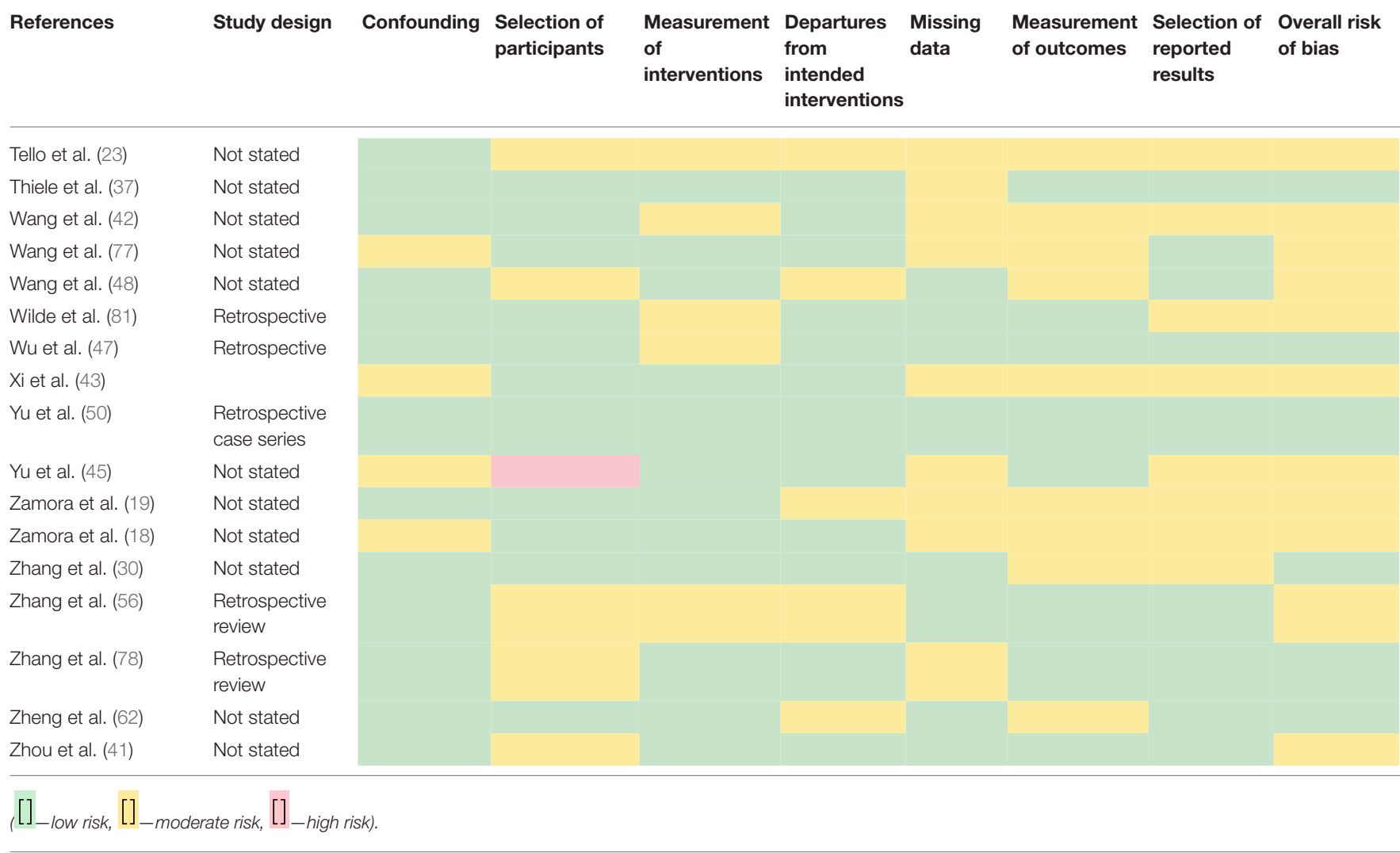

TABLE 3 | Risk-of-bias asssessment on trial studies.

\begin{tabular}{lllllll}
\hline References & Study design & $\begin{array}{l}\text { Sequence } \\
\text { generation }\end{array}$ & $\begin{array}{l}\text { Allocation } \\
\text { concealment }\end{array}$ & $\begin{array}{c}\text { Blinding } \\
\text { Incomplete } \\
\text { data }\end{array}$ & $\begin{array}{l}\text { Selective } \\
\text { reporting }\end{array}$ & $\begin{array}{l}\text { Other sources } \\
\text { Overall risk } \\
\text { of bias }\end{array}$ \\
\hline Ayoub et al. (44) & $\begin{array}{l}\text { Randomized and } \\
\text { prospective }\end{array}$ & & & \\
El-Fiky et al. (35) & Prospective & & \\
Fan et al. (75) & Prospective \\
Kolk et al. (76) & Prospective \\
Schimming et al. (39) & Prospective \\
Schimming et al. (38) & Prospective \\
Shan et al. (46) & Prospective & & \\
Tarsitano et al. (34) & Prospective & & \\
Tenhagen et al. (20) & Prospective & & \\
Tsao et al. (66) & Prospective \\
Weijs et al. (49) & Prospective & & \\
\hline
\end{tabular}

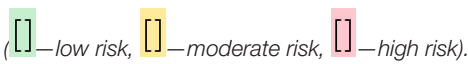

that paper was deemed "seminal" in nature due to the technique utilized or significance of the study.

\section{Computed Tomography Scanning Systems}

1. Wilde et al. Intraoperative imaging with a 3D C-arm system after zygomatico-orbital complex fracture reduction (81)

Impact Factor 5.38.

\section{Intraoperative 3D CT C-Arm System}

The purpose was to investigate whether intraoperative $3 \mathrm{D}$ C-arm imaging is effective technique for assessing the adequacy of fracture reduction in the management of uncomplicated ZMC fractures. They found that the use of $3 \mathrm{D} \mathrm{CT}$ to assess fracture reduction intraoperatively shows to be an effective tool for evaluating ZMC fracture reduction. Therefore, avoiding additional procedures or need for further imaging. 
TABLE 4 | Imaging and printing techniques used in the studies.

\begin{tabular}{|c|c|c|}
\hline References & Study type & Imaging acquisition and technique \\
\hline \multicolumn{3}{|l|}{ Cephalic } \\
\hline Heissler et al. (17) & Bony skull defects & $\begin{array}{l}\text { Transversal 2-mm spiral CT with 3D reconstruction } \\
\text { of the cranium were made. }\end{array}$ \\
\hline Zamora et al. (18) & Cephalometric landmarks & $\begin{array}{l}\text { Patients were selected who had both an LRC and a } \\
\text { CBCT. }\end{array}$ \\
\hline Zamora et al. (19) & Cephalometric landmarks & Scan using the "i- CAT" cone bean system \\
\hline $\begin{array}{l}\text { Tenhagen et al. } \\
\text { (20) }\end{array}$ & $\begin{array}{l}\text { Calvarial recon for } \\
\text { scaphocephaly }\end{array}$ & $\begin{array}{l}\text { 3D handheld scanning photography (M4D Scan 3D } \\
\text { scanner by Rodin4D, Vxelements software) vs. } \\
\text { planar x-ray }\end{array}$ \\
\hline Guo et al. (21) & $\begin{array}{l}\text { Condylar head fracture } \\
\text { preoperative planning }\end{array}$ & $\begin{array}{l}\text { All patients underwent CBCT preoperatively, and } \\
\text { Digital Imaging and Communications in medicine } \\
\text { (DICOM) files were imported into Simplant } 11.04 \\
\text { software. }\end{array}$ \\
\hline
\end{tabular}

Broumand et al.

(22)

Tello et al. (23)

Eppley (24)

Klenk and Kovacs

(25)

Rabie et al. (26)

Gui et al. (27)

Gerbino et al. (28)

Craniofacial fractures and open reduction

Facial trauma recon

Cranial or cranio-orbital recon

Ct for facial fracture/bony pathology

Facial fractures

Craniofacial fibrous

dysplasia recontouring

Fronto-orbito-pterional craniotomy

Schmutz et al. (29) Imaging orbital fractures Zhang et al. (30) Craniomaxillofacial bone defects

Andrews et al. (31) Craniomaxillofacial surgery

Suzuki-Okamura Le Fort 1 and sagittal split et al. (32)

Liu et al. (33) ramus osteotomies Complex craniomaxillofacial surgery

Tarsitano et al. (34) Disarticulation resection surgery for mandibular tumor, reconstructive plate supporting fibular microvascular free flap

El-Fiky et al. (35) Le Fort fracture imaging
CT scans performed on a General Electric 9,800 CT scanner

Patients were studied with either CCT or SCT of the face after trauma.

Preoperatively, a 3D CT scan (1-mm cuts) was obtained from which an anatomical model was fabricated. On the anatomical model, the predicted amount of bone excision was performed.

Patients' radiographs and CT scans were reviewed to establish the clinical value of 3D CT.

The XCAT ENT was used to provide images

Preoperative and postoperative spiral CT data

Preoperative Spiral CT

MRI based virtual 3D models of the intact orbit CT (slice thickness $0.625 \mathrm{~mm}$ ), computer-aided design/computer-aided manufacturing and $3 \mathrm{D}$ reconstruction, as well as rapid prototyping were performed.

All subjects undergo a fine cut noncontrast maxillofacial CT scan with 0.5- to 1-mm slice cuts.

3D CT images taken before and after surgery were superimposed by $3 \mathrm{D}$ imaging software.

Spiral CT data sets (light speed 16, General Electric, Fairfield, CT; 0.625-mm slice thickness) were acquired for all patients preoperatively.

Planning and postoperative CT scans were superimposed to assess the accuracy of reconstruction.

Virtual planning began with acquisition of high-resolution CT scans of the craniofacial region and the lower legs (the donor site)

All patients subjected to non-contrast MSCT in axial cuts. Multiplanar reformatted (MPR) images were acquired using the machine software in sagittal and coronal planes.

\section{Printer}

Number of Mean Age

patients
15

9

18

9

13

A tape of the scan was sent to the manufacturer and a 3D model generated. polyetheretherketone (PEEK) used to manufacture implants Surgical guides and implants produced using rapid prototyping technologies.

The customized HA/EAM compound artificial implants were manufactured through selective laser sintering using a rapid prototyping machine into the exact geometric shapes of the defect. 
TABLE 4 | Continued

\begin{tabular}{|c|c|c|}
\hline References & Study type & Imaging acquisition and technique \\
\hline Tel et al. (36) & Craniofacial surgery & $\begin{array}{l}\text { Preoperative CT, Digital Imaging and } \\
\text { Communications (DICOM) files imported into } \\
\text { Anatomage InVivo software for segmentation. } \\
\text { Postoperative CT evaluated procedure accuracy. }\end{array}$ \\
\hline Thiele et al. (37) & Craniomaxillofacial recon & $\begin{array}{l}\text { In all cases, CBCT datasets were uploaded online in } \\
\text { DICOM format via a secured website. Implants were } \\
\text { designed from these datasets using OsiriX and/or } \\
\text { Mimics Medical } 19.0 \text { software. The titanium plates } \\
\text { were 3D printed using the selective titanium laser } \\
\text { sintering method. }\end{array}$ \\
\hline
\end{tabular}

\section{Mandibular}

Schimming et al. (38)

Recon with microvascular bone graft

Schimming et al. Assess mandibular bone (39)

Suzuki et al. (40) Cancer resection and reconstruction

Zhou et al. (41)

Defect repair and autogenous bone graft

Wang et al. (42) Block resection mandible and recon with fibular flap

Xi et al. (43)

Ayoub et al. (44)

Reconstruction with iliac crest bone graft

Condyle recon
Yu et al. (45)

Guo et al. (21)

Shan et al. (46)
CBCT datasets were obtained by scanning the patients seated in the natural head position using a standard CBCT scanning

Patients randomly allocated into two equal groups using the computer program RandList (DatInf $\mathrm{GmbH}$, Tübingen, Germany). Virtual surgical planning was based on preoperative CT-data using specific surgical planning software [ProPlan CMF (Materialize NV, Leuven, Belgium)]. A rapid prototyping guide transferred the virtual surgery plan to the operation site. To compare pre and postoperative condyle position, intercondylar distance was measured using 3D models of the mandible before and after surgery. Models were imported into the Geomagic Studio software (Geoma- gic, Morrisville, NC, USA) using the STL-format.

Condylar resection and condylectomy

Condylar head fracture preoperative planning

Reconstruction with fibula flap was obtained for all patients.

All patients underwent CBCT preoperatively, and Digital Imaging and Communications in medicine (DICOM) files were imported into Simplant 11.04 software.

Computed tomography (CT) scan, preoperative design, and operation on the mandible were done.
A preoperative thin-cut $(1.25 \mathrm{~mm})$, spiral CT scan
Printer

Anatomical models were 3D

printed using conventional

$3 \mathrm{D}$ printers and sent to the hospital by post, along with the PSIs
Number of Mean Age

patients

3

51

60

20

The tray was manufactured

in the LPS 600 laser

prototyping type of stereolithography system

A physical resin model of the reconstructed mandible was manufactured using the SPS350 laser stereolithography prototyping system 
TABLE 4 | Continued

\begin{tabular}{|c|c|c|c|c|c|}
\hline References & Study type & Imaging acquisition and technique & Printer & $\begin{array}{l}\text { Number of } \\
\text { patients }\end{array}$ & Mean Age \\
\hline Wu et al. (47) & $\begin{array}{l}\text { Reconstruction with fibula } \\
\text { free flap }\end{array}$ & $\begin{array}{l}\text { Computed tomography }(\mathrm{CT}) \text { scanning was } \\
\text { performed using a } 64 \text {-slice CT unit. The CT data of } \\
\text { the skull and the fibula were transferred to the } \\
\text { ProPlan CMF } 1.4 \text { software. }\end{array}$ & & 8 & 32.6 \\
\hline Wang et al. (48) & $\begin{array}{l}\text { Reconstruction with } \\
\text { vascularized fibula graft }\end{array}$ & ProPlan CMF surgical planning software & & 56 & 52 \\
\hline Weijs et al. (49) & $\begin{array}{l}\text { Segmental resection (with } \\
\text { fibular free flap - not } \\
\text { evaluated) }\end{array}$ & $\begin{array}{l}\text { Preoperatively, a CBCT scan was acquired to } \\
\text { delineate the size and extension of tumor invasion; } \\
\text { patients in natural head position, using a standard } \\
\text { CBCT scanning protocol. }\end{array}$ & & 11 & 68 \\
\hline Yu et al. (50) & $\begin{array}{l}\text { Mandibulectomy and } \\
\text { mandibular recon with free } \\
\text { fibula flap }\end{array}$ & $\begin{array}{l}\text { The process of CAD began with the acquisition of } \\
\text { high-resolution CT scans of the maxillofacial } \\
\text { skeleton and lower extremities. The imaging and } \\
\text { planning plat- form used in this study was Surgicase } \\
\text { CMF }\end{array}$ & & 29 & 33 \\
\hline Fu et al. (51) & Contour surgery & $\begin{array}{l}\text { Perform VSP based on 3D computed tomography } \\
\text { (CT) data. }\end{array}$ & & 20 & 25.4 \\
\hline Mascha et al. (52) & $\begin{array}{l}\text { Reconstruction with } \\
\text { vascularized and } \\
\text { non-vascular bone graft }\end{array}$ & $\begin{array}{l}\text { Mandibular reconstruction with the PSMP-method. } \\
\text { Preoperative and postoperative CT scans were } \\
\text { evaluated by measuring distances between } \\
\text { corresponding landmarks on the mandibular rami. } \\
\text { The difference was used to evaluate reconstruction } \\
\text { accuracy. }\end{array}$ & & 18 & 65 \\
\hline $\begin{array}{l}\text { Sawh-Martinez } \\
\text { et al. (53) }\end{array}$ & $\begin{array}{l}\text { Reconstruction of TMJ } \\
\text { position }\end{array}$ & Preoperative CT of the mandible in all patients & & 16 & 61.6 \\
\hline Kraeima et al. (54) & Reconstruction & $\begin{array}{l}\text { Each patient underwent diagnostic work-up } \\
\text { consisting of both a CT and MRI of the head and } \\
\text { neck region according to the clinical protocol. }\end{array}$ & & 34 & 69.9 \\
\hline Davies et al. (55) & Reconstruction & $\begin{array}{l}\text { High-resolution CT scans were acquired using } \\
\text { multidetector CT with standard protocols exhibiting } \\
\text { nearly isotropic 3D spatial resolution for the facial } \\
\text { bones. The image voxel size was } 0.47 \mathrm{~mm}^{3} \text {. }\end{array}$ & & 10 & 55 \\
\hline Zhang et al. (56) & $\begin{array}{l}\text { Reconstruction with iliac } \\
\text { crest flap }\end{array}$ & $\begin{array}{l}\text { All patients consented to undergo 3D CT and image } \\
\text { reconstruction, mirror imaging design, 3D model } \\
\text { prototyping, CTA, fabrication of an individual } \\
\text { preformed reconstruction plate, and iliac crest flap } \\
\text { design before surgery. }\end{array}$ & & 19 & 15.8 \\
\hline Reiser et al. (57) & $\begin{array}{l}\text { Oromandibular recon (virtual } \\
\text { resection and free fib flap) }\end{array}$ & CT was obtained & $\begin{array}{l}\text { V-stand is 3D printed using } \\
\text { biocompatible plastic } \\
\text { polymers. }\end{array}$ & 17 & 53 \\
\hline \multicolumn{6}{|l|}{ Maxillary surgery } \\
\hline Ohkawa et al. (58) & Maxillofacial fractures & $\begin{array}{l}\text { 2D CT and 3D CT with helical CT scanning were } \\
\text { performed using Toshiba Xvigor scanner. }\end{array}$ & & 21 & \\
\hline Tao et al. (59) & $\begin{array}{l}\text { Maxillary and mandibular } \\
\text { tumors }\end{array}$ & $\begin{array}{l}\text { In this study, the maxillofacial tumors were } \\
\text { subjected to a mimic operation on a computer } \\
\text { following CT scanning and 3D reconstruction. }\end{array}$ & & 10 & 45 \\
\hline Shaye et al. (60) & Maxillofacial recon & $\begin{array}{l}\text { Intraoperative CT scans were obtained for all } \\
\text { patients. }\end{array}$ & & 38 & 37.4 \\
\hline Tarsitano et al. (61) & $\begin{array}{l}\text { Maxillary recon with fibular } \\
\text { flap }\end{array}$ & $\begin{array}{l}\text { Preoperative high-resolution CT data set used for } \\
\text { virtual planning was superimposed onto the } \\
\text { postoperative CT }\end{array}$ & $\begin{array}{l}\text { Reconstructive titanium } \\
\text { mesh was manufactured by } \\
\text { a direct metal laser sintering } \\
\text { (DMLS) method. The } \\
\text { solid-to-layer files of the } \\
\text { guide and plate were then } \\
\text { manufactured by DMLS } \\
\text { using an EOSINT M270 } \\
\text { system }\end{array}$ & 4 & \\
\hline Zheng et al. (62) & Maxillary reconstruction & CT data processed using Mimics 10.01 software & $\begin{array}{l}\text { 3D printer to print all } \\
\text { templates. }\end{array}$ & 6 & 35.6 \\
\hline
\end{tabular}


TABLE 4 | Continued

\begin{tabular}{ll}
\hline References & Study type \\
\hline Frellesen et al. (63) & Maxillofacial trauma \\
Orbital and zygomatic \\
Kwon et al. (64) $\quad$ Orbital blowout fractures \\
Novelli et al. (65) $\quad$ Orbital recon
\end{tabular}

Tsao et al. (66)

Orbital wall fracture and recon with bone graft

Tabakovic et al. Orbital floor blowout

(67) fractures

Tarsitano et al. (68) Recon orbital floor fracture

Gander et al. (69) Zygomatic fracture

Gibelli et al. (70) Normal zygomatic bone imaging

Sozzi et al. (71) Orbital wall recon for craniofacial trauma

Kim et al. (72)

Orbital fracture

Dong et al. (73)

Orbital wall fracture recon

\section{Complex surgeries}

Heiland et al. (74) Zygomaticomaxillary complex fracture

Fan et al. (75)
Complex orbital fracture
Imaging acquisition and technique

Printer

Second-generation DSCT

Number of

Mean Age

patients

120

29.975

Facial CT scans before and after surgery.

DICOM data was captured with a maxillofacial CT scanner that produces $0.8 \mathrm{e} 1 \mathrm{~mm}$ slices. The CT was acquired after positioning the patient's landmarks in order to orient the patient in space during surgical navigation. Stereolithographic mode was manufactured by exporting the patient's STL file of the skull and of the maxillofacial regions.

Orbital reconstruction with radiopaque grafts (bone, titanium-reinforced polyethylene, and titanium plate) and assessed postoperatively with orbital CBCT (CS 9300; Carestream Health Inc., Rochester, NY).

Waters occipitomental view $\mathrm{x}$-ray, 3D

The STL model was printed by ZPrinter 310 (a rapid prototyping machine) through an additive technique using deposition of chalk

High-resolution CT scan of the patient's craniofacial skeleton. Imaging was performed using a multidetector CT scanner The solid-to-layer files of the mesh were then manufactured using direct metal laser sintering, which resolves the shaping and bending biases inherent in the indirect method.

Preoperative multislice CT Intraoperative 3D CBCT

$3 \mathrm{D}$ models of the zygomatic bone acquired through segmentation on CT scans

Reconstructed orbits from patients and control subjects were segmented from the postoperative CT scans. Postoperative CT scan 1 day ( $0-2$ days) after reconstructive surgery using a 16-slice CT (Brilliance $®$ Philips, Milan, Italy) with 2-mm thickness, $1 \mathrm{~mm}$ increment acquisition, $1.5-\mathrm{mm}$ thickness, 0.75-mm increment images reconstruction.

Pseudoforamina of the orbital wall were offset with the segmented sinuses. Finally, the 3D facial bone model, with orbital wall, was reconstructed from the segmented images. The CT data sets comprised slice images ranging from 171 slices to 246 slices.

The HA/PLLA implant was delivered in the form of a composite sheet, 0.3 or $0.5 \mathrm{~mm}$ in thickness, and a bone fixation tack system. Specifically, the preoperative CT images were imported into the workstation while the camera was pointed at the anticipated surgical site.

Intraoperatively, after open reduction, a cone-beam CT (CBCT) dataset was generated using the SIREMOBIL ISO-C3D

CAD/CAM technique based on Helical CT

\begin{tabular}{|c|c|c|}
\hline & 4 & 49.5 \\
\hline & 10 & 30 \\
\hline & 7 & \\
\hline & 48 & 53.04 \\
\hline & 100 & 45.3 \\
\hline & 20 & 41.6 \\
\hline & 10 & 45 \\
\hline & 10 & 57.5 \\
\hline & 14 & 43.9 \\
\hline $\begin{array}{l}\text { orous polyethylene } \\
\text { naterials were shaped and } \\
\text { serted into the orbit to } \\
\text { epair the orbital wall defect } \\
\text { nd correct the } \\
\text { nophthalmos. }\end{array}$ & 17 & 32.2 \\
\hline
\end{tabular}


TABLE 4 | Continued

\begin{tabular}{|c|c|c|c|c|c|}
\hline References & Study type & Imaging acquisition and technique & Printer & $\begin{array}{l}\text { Number of } \\
\text { patients }\end{array}$ & Mean Age \\
\hline Kolk et al. (76) & Complex orbital recon & $\begin{array}{l}\text { MSCT (Somatom Volume Zoom scanner, Sensation } \\
\text { 16, Siemens Medical Solutions, Erlangen, Germany) } \\
\text { and MR images as well as corresponding 3D } \\
\text { reconstructions were used to assess the site and } \\
\text { size of bony and soft tissue changes in the } \\
\text { traumatized orbits. }\end{array}$ & & 37 & 30.6 \\
\hline Wang et al. (77) & $\begin{array}{l}\text { Recontouring of } \\
\text { craniomaxillofacial fibrous } \\
\text { dysplasia }\end{array}$ & $\begin{array}{l}\text { Preoperative thin-cut }(0.625 \mathrm{~mm}) \text {, spiral CT scans } \\
\text { were obtained. }\end{array}$ & & 13 & 27.3 \\
\hline Zhang et al. (78) & TMJ replacement surgery & $\begin{array}{l}\text { 3D CT scanning with a 16-spiral imager (0.625-mm } \\
\text { slice thickness; LightSpeed Ultra; General Electric, } \\
\text { Milwaukee, WI) of the craniofacial skeleton. The } \\
\text { data from CT scanning in DICOM (Digital Imaging } \\
\text { and Communications in Medicine) format were input } \\
\text { into the interactive Simplant CMF software program } \\
\text { (Materialize Medical, Leuven, Belgium). Preoperative } \\
\text { planning included segmentation and osteotomies. } \\
\text { The movements of the jaw bones were simulated by } \\
\text { use of Simplant CMF. The affected mandible was } \\
\text { reconstructed based on the contralateral side. The } \\
\text { titanium plate was shaped on the reconstructed } \\
\text { model before surgery. The bone graft was } \\
\text { transplanted by the shaped titanium plate during the } \\
\text { operation to reconstruct the TMJ. }\end{array}$ & & 11 & 42.3 \\
\hline $\begin{array}{l}\text { Myga-Porosiło } \\
\text { et al. (79) }\end{array}$ & Traumatic facial fractures & CT with a "Hispeed" unit & & 67 & 35 \\
\hline Lim et al. (80) & $\begin{array}{l}\text { Temporal bone fracture (and } \\
\text { facial nerve paralysis) }\end{array}$ & $\begin{array}{l}\text { A high-resolution CT scan of the temporal bone was } \\
\text { obtained in 1-mm sections with a CT scanner. }\end{array}$ & & 12 & 36.7 \\
\hline Wilde et al. (81) & $\begin{array}{l}\text { Zygomatico-orbital complex } \\
\text { fracture repair }\end{array}$ & $\begin{array}{l}\text { Preoperative MSCT by use of multiplanar view } \\
\text { reduction and internal fixation through an intraoral } \\
\text { maxillary vestibular approach. Intraoperative 3D } \\
\text { C-arm imaging }\end{array}$ & & 21 & 44 \\
\hline An et al. (82) & $\begin{array}{l}\text { Resection of orbital } \\
\text { craniofacial fibrous dysplasia }\end{array}$ & $\begin{array}{l}\text { A preoperative 3D CT examination After CT } \\
\text { scanning, the skulls were reconstructed in 3D using } \\
\text { analytic software. }\end{array}$ & & 5 & 22.6 \\
\hline Shan et al. (83) & $\begin{array}{l}\text { Maxillary and mandibular } \\
\text { reconstruction }\end{array}$ & $\begin{array}{l}\text { High-resolution CT of maxillofacial and fibula } \\
\text { regions. }\end{array}$ & & 4 & \\
\hline Farook et al. (84) & $\begin{array}{l}\text { Traumatic cranial and facial } \\
\text { fractures }\end{array}$ & $\begin{array}{l}\text { Patients were scanned in a Philips Ingenuity Core } \\
128 \text { Slice CT Machine with appropriate brain and } \\
\text { facial protocols with bone and soft tissue } \\
\text { reconstruction. }\end{array}$ & & 100 & 32 \\
\hline Kokosis et al. (85) & Complex mandibular recon & $\begin{array}{l}\text { The initial CT scans were reviewed by our team, and } \\
\text { VSP was undertaken using specialized software }\end{array}$ & & 5 & \\
\hline Guest et al. (86) & Skull components & $\begin{array}{l}\text { A 3D model was produced for each of the seven } \\
\text { participating patients based on preoperative } \\
\text { cross-sectional imaging. }\end{array}$ & $\begin{array}{l}\text { STL files were printed using } \\
\text { a Stratasys uPrint SE Plus. }\end{array}$ & 7 & 30.7 \\
\hline
\end{tabular}

CBCT, cone-bean computed tomography; CCT, conventional computed tomography; CT, computed tomography; CTA, computed tomography angiography; DSCT, dual-source computed tomography; HAVEAM, hydroxyapatite combined with epoxide acrylate maleic; HAVPLLE - hydroxyapatite combined with poly-I-lactide; LRC, Iocoregional treatment; MSCT,

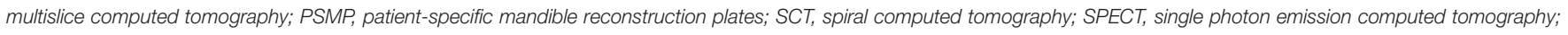
VSP, virtual surgical planning.

Bias limitations: Moderate risk of bias from the measurement of interventions (retrospective review).

2. Ayoub et al. Evaluation of computer-assisted mandibular reconstruction with vascularized iliac crest bone graft compared to conventional surgery: a randomized prospective clinical trial (44)

\section{Impact factor 5.29.}

\section{Computer Assisted vs. Conventional Surgery}

Virtual surgical planning was based on preoperative CT-data using specific surgical planning software. A rapid prototyping guide transferred the virtual surgery plan to the operation site.

The purpose/aim of this study was to evaluate the benefits of computer-assisted mandibular reconstruction with iliac crest bone grafts. It compared the following areas:

- Intraoperative time for transplant shaping 


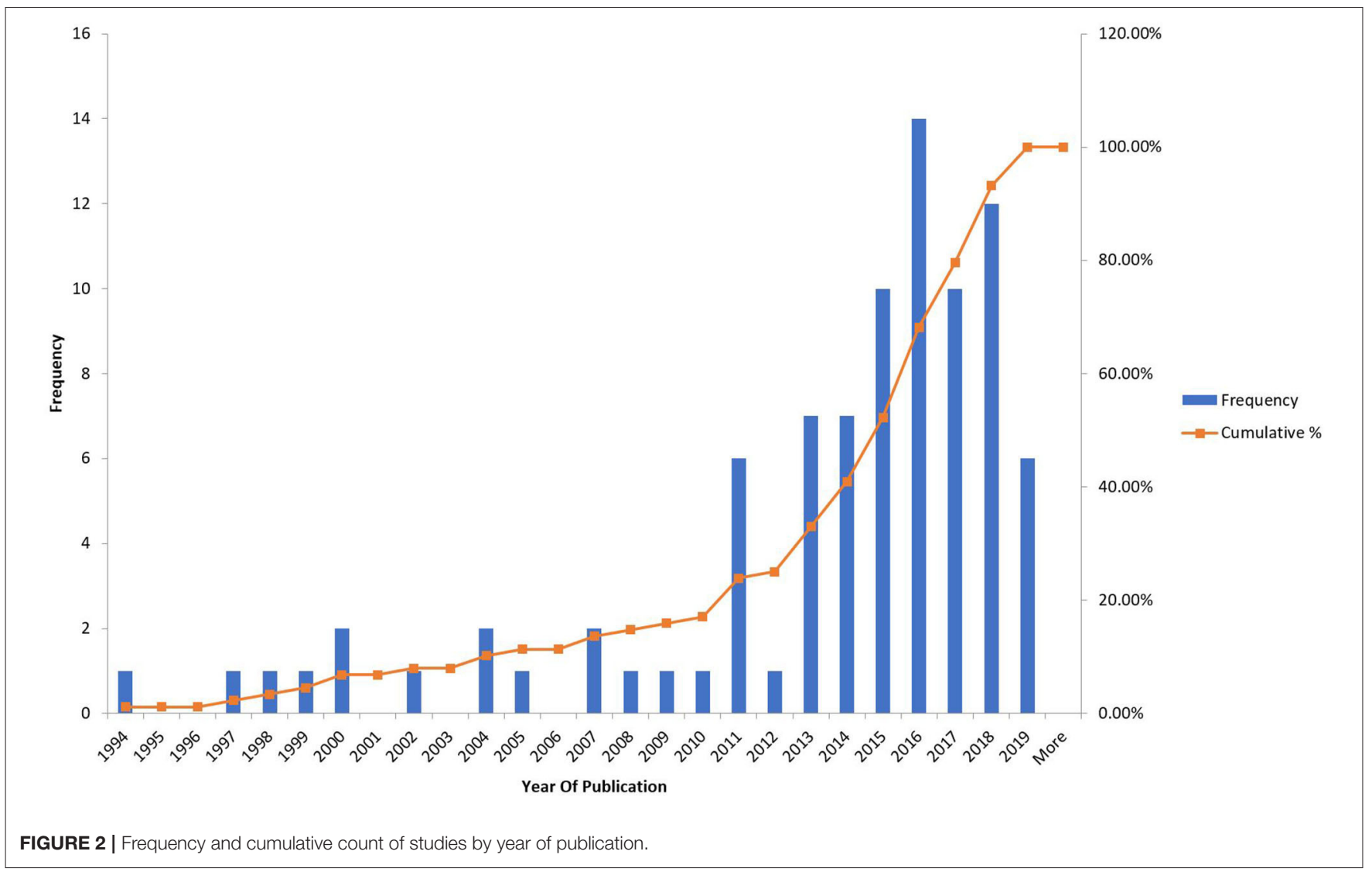

- Ischemia

- Duration of surgery

- Amount of bone removed

- Change in postoperative condyle position compared to conventional surgery.

This is the first randomized prospective study comparing computer-assisted mandibular reconstruction with conventional surgery using iliac crest bone grafts.

The study shows that computer-assisted reconstruction reduces ischemic time and transplant-shaping time at the defect site as well as requiring a smaller amount of harvested bone than conventional surgery. Moreover, a significantly smaller alteration in condyle position could be shown in the computerassisted group.

Bias limitations: High risk of bias from the blinding technique (trial format study).

3. Heiland et al. Intraoperative imaging of zygomaticomaxillary complex fractures using a 3D C-arm system (74)

\section{Impact factor 3.69 .}

\section{Intraoperative 3D CT C-Arm System}

Purpose/aim of the study was to investigate in a first series patients with ZMC fractures, the practicability and value of intraoperative imaging using the 3D CT C-arm (SIREMOBIL Iso-C3D) after open reduction.

They showed that this interoperative imaging technique provided suitable visualization of the facial skeleton postoperatively. This study was done in 2004; therefore, image processing took longer to generate and would not be a technical limitation if carried out now. This paper has similar ideals to Wilde et al. but is important to mention as it paved the way for much of the current modern work.

Bias limitations: Moderate risk of bias from the measurement of interventions (retrospective review).

4. Zhou et al. Accurate reconstruction of discontinuous mandible using a reverse engineering/computer-aided design/rapid prototyping technique: a preliminary clinical study (41)

\section{Impact factor 5.09 .}

\section{Reverse Engineering (RE), Computer-Aided Design (CAD), and Rapid Prototyping (RP)}

The aim/purpose of the study was to improve surgical outcomes in discontinuous mandibular defects by fabricating patientspecific customized titanium mandibular trays. The was done by utilizing reverse engineering (RE), computer-aided design (CAD) and rapid prototyping (RP) techniques by firstly obtaining a virtual $3 \mathrm{D}$ model via spiral CT scanning - the opposite side of the mandible was mirrored to cover the defect area to restore excellent facial symmetry. They then used autogenous bone grafting to restore the bony continuity for occlusion rehabilitation.

The trays fabricated using this technique fitted well in all six patients. The reconstructive procedures were easy and time saving. Satisfactory facial symmetry was restored. No severe 
complications occurred in the five patients without occlusion rehabilitation during a mean 50-month follow-up period. The reconstruction in the patient with occlusion lasted for only 1 year and failed eventually because of bone resorption and infection.

Satisfactory aesthetic results were achieved. However, the rigidity of the cast tray could cause severe stress shielding to the grafts, which could lead to disuse atrophy. A promising technique but some modification is needed for functional reconstruction.

Bias limitations: Moderate risk of bias from the selection of participants (retrospective review).

5. Shaye et al. Use of intraoperative computed tomography for maxillofacial reconstructive surgery (60)

\section{Impact factor 3.67 .}

\section{Intraoperative 3D CT C-Arm System}

Aim/purpose of the study is to evaluate the time needed to perform intraoperative CT scans during maxillofacial surgery. In addition, they looked to see if there were any trends toward shorter total scan times as experience is gained with the technique. They also looked to identify the characteristics of cases that required intraoperative revision based on the results of intraoperative CT scanning.

\section{Conclusions}

- Current intraoperative CT scanning techniques are rapid, averaging 14.5 min per case (in 38 cases).

- No decrease in total scan time was noted during the study; however, the surgeon most experienced with the CT software had the shortest total scan times.

- Intraoperative revisions were most common in complex cases.

Recommendation from the study is that surgeons consider the use of intraoperative CT imaging for maxillofacial reconstruction, particularly in complex procedures.

Bias limitations: High risk of bias from the measurement of outcomes and selection of reported results (retrospective review).

6. Wang et al. Mandibular reconstruction with the vascularized fibula flap: comparison of virtual planning surgery and conventional surgery (48)

\section{Impact factor 5.6.}

\section{Virtual Planning vs. Conventional Surgery}

The aim/purpose of this study was to evaluate the accuracy of mandibular reconstruction and assessed clinical outcomes in both virtual planning and conventional surgery patients.

The main outcomes measured:

- Operative time

- Ischemia time

- Postoperative CT scans

- Facial appearance and occlusal function.

The ischemia time and total operation time were shorter in the virtual planning group than in the conventional surgery group.

High precision with the use of the cutting guides and templates was found for both the fibula and mandible, and a good fit was noted among the pre-bent plate, mandible, and fibula segments in the virtual planning group. Postoperative CT scans also showed excellent mandibular contours of the fibula flaps in accordance with virtual plans in the virtual planning group.

Surgical planning software (ProPlan CMF) was used preoperatively in the virtual planning group. In the virtual planning group, fibula flaps were harvested and osteotomized, and the mandibles were resected and reconstructed assisted by the prefabricated cutting guides and templates.

This study demonstrated that virtual surgical planning was able to achieve more accurate mandibular reconstruction than conventional surgery. The use of prefabricated cutting guides and plates makes fibula flap molding and placement easier, minimizes the operating time, and improves clinical outcomes.

Bias limitations: Medium risk of bias from the selection of participants, missing data, measurement of outcomes, and selection of reported results (retrospective review).

7. Wang et al. Three-dimensional virtual technology in reconstruction of mandibular defect including condyle using double-barrel vascularized fibula flap (42)

\section{Impact factor 5.38 .}

\section{D Virtual Planning}

The aim/purpose of this study is to look at the impact of using $3 \mathrm{D}$ virtual surgical planning technology on surgical outcomes in the reconstruction of mandibular defects-specifically, type $\mathrm{H}$ mandibular defects including the condyle using a double-barrel vascularized fibula flap.

The simulation allowed for the construction of an individual mandibular model serving to guide the clinical operation. They found preoperative virtual surgery greatly benefitted the actual surgery. In addition, postoperative $3 \mathrm{D}$ reconstruction revealed a close match with the simulated condyle. Therefore, combined virtual $3 \mathrm{D}$ reconstruction and rapid prototyping can improve postoperative outcomes in mandibular reconstruction.

Bias limitations: Medium risk of bias from the selection of participants, missing data, measurement of outcomes, and selection of reported results (retrospective review).

8. Zhang et al. Evaluation of alveolar bone grafting using limited cone beam computed tomography (56)

Impact factor 3.11 .

\section{Limited Cone Beam CT (LCBCT)}

The aim/purpose of the study is to look at the use of limited $\mathrm{CBCT}$ and subsequent $3 \mathrm{D}$ reconstruction to monitor bone resorption in alveolar bone grafts in patients with an alveolar cleft.

They found that LCBCT scan and $3 \mathrm{D}$ reconstruction is a promising method for evaluation of the outcome of alveolar bone grafts.

One of the first and only uses of limited cone beam and grafting combination.

Bias limitations: Medium risk of bias from the measurement of interventions and departure from the intended interventions (retrospective review). 
9. Heissler et al. Custom-made cast titanium implants produced with CAD/CAM for the reconstruction of cranium defects (17)

\section{Impact factor 3.87 .}

\section{D Spiral CT With CAD/CAM to Produce Custom-Made Titanium Implants}

The aim/purpose of this paper was to use 3D spiral CT to design titanium implants for bony skull defects. They used rapid prototyping for a fine casting process-the first group to do this.

One of the first papers to use spiral CT with CAD/CAM to create custom-made cast titanium implants for the reconstruction of cranium defects. They showed that this method is superior for several reasons for the patient and the surgeon:

- Complex geometrical structures with small diameters can be produced with significantly more precision than previously.

- The rim of the implant can be designed in such a way that it extends over the edge of the bone - this leads to good stability at the bone-implant interface.

- The results are predictable and aesthetically very pleasing.

- Operating time and the trauma caused by the operation are considerably less compared with techniques using autologous bone

Bias limitations: Medium risk of bias from the selection of participants, missing data, measurement of outcomes, and selection of reported results (retrospective review).

10. Yu et al. Three-Dimensional Accuracy of Virtual Planning and Surgical Navigation for Mandibular Reconstruction with Free Fibula Flap (50)

\section{Impact factor 3.2.}

\section{CAD Surgical Navigation}

The aim/purpose of the paper was to see if the use of $\mathrm{CAD}$ and surgical navigation improved the surgical outcomes and operations in free fibula flap mandible reconstruction for patients with benign tumors who underwent primary unilateral reconstruction.

They found that when including computer-aided design (CAD), CAD guided mandibular angle remodeling and condyle placement with increased accuracy. In addition, CAD and surgical navigation increase reconstruction accuracy without prolonging operative time.

Bias limitations: No risk of bias limitations (retrospective review).

\section{Magnetic Resonance and Handheld Scanning Imaging Modalities}

1. Schmutz et al. Magnetic resonance imaging: an accurate, radiation-free, alternative to computed tomography for the primary imaging and three-dimensional reconstruction of the bony orbit (29)

\section{Impact factor 2.}

\section{MRI vs. CT}

The aim/purpose of the study is to compare the accuracy of MRI based virtual 3D models of the intact orbit can approach that of the gold standard, CT-based models. This is to identify whether MRI is a viable alternative to CT scans in patients with isolated orbital fractures and penetrating eye injuries, pediatric patients, and patients requiring multiple scans in whom radiation exposure is ideally limited.

Patients who presented with unilateral orbital fractures to a hospital in a 1-year period were recruited. The outcome measurements were orbital volume (primary outcome) and geometric intra-orbital surface deviations (secondary outcome) between the MRI- and CT-based 3D models.

The volumetric differences of the MRI models are comparable to reported results from CT models. The intra-orbital MRI surface deviations are smaller than the accepted tolerance for orbital surgical reconstructions. Therefore, the authors believe that MRI is an accurate radiation-free alternative to CT for the primary imaging and $3 \mathrm{D}$ reconstruction of the bony orbit.

Bias limitations: High risk of bias from the selection of participants, missing data, and measurement of outcomes (retrospective review).

2. Tenhagen et al. Three-Dimensional Handheld Scanning to Quantify Head-Shape Changes in Spring-Assisted Surgery for Sagittal Craniosynostosis (20)

\section{Impact factor 2.8 .}

\section{3d Handheld Scanning and Postprocessing Imaging Techniques}

The aim/purpose of the study was to assess the utility of 3D handheld scanning photography in a patient group which underwent spring-assisted correction surgery for scaphocephaly. Usually, the gold standard for acquiring 3D imaging is CT that entails ionizing radiations and, in young children, a general anesthesia. 3D photographic imaging is an alternative method to assess patients who have undergone calvarial reconstructive surgery.

They did Pre- and postop 3D scans acquired in theater, they then repeated these at the 3 -week follow-up in clinic; images were then postprocessed for nine patients.

The following parameters were looked at:

- Cephalic index (CI)

- Head circumference

- Volume

- Sagittal length

- Coronal width over the head

Statistical shape modeling (SSM) was used to calculate the $3 \mathrm{D}$ mean anatomical head shape, no significant differences were observed in the $\mathrm{CI}$ between $3 \mathrm{D}$ and $\mathrm{x}$-ray. Therefore, 3D handheld scanning followed by SSM proved to be an efficacious and practical method to evaluate $3 \mathrm{D}$ shape outcomes after springassisted cranioplasty in individual patients and the populationso a good alternative (or at least as a follow up) to CT. 
Bias limitations: Medium risk of bias from the sequence generation, allocation concealment, and blinding (trial format study).

\section{CONCLUSION}

The field of facial imaging techniques for bony reconstruction can be seen to be clearly computed tomography heavy, but some small gains have been made in the magnetic resonance and handheld field.

One could think that with such a large analysis of the literature, it could serve as a guide for those looking to plan preoperatively. However, this would merely be sweeping generalizations of the technologies available. There are several things that are clear and should help when planning surgical intervention. The use of CT is the most commonly used modality for bony injuries and defects due to its availability, versatility (with modifications such as angiography) and accuracy. The emergence of technologies such as CAD lend themselves to using CT and provide an extra level of preoperative data. Similar to CT, MRI has many of these of these benefits, but for purely bone based planning it would not be the modality of choice. Depending on the situation of the patient (such as renal issues), MRI may end up being the image technique of choice and luckily it is robust enough to be of benefit. To make full use of the analysis carried out in this work, one should attempt to tailor their case to those papers with similar patient populations and intended outcomes.

\section{REFERENCES}

1. Tzou CH, Artner NM, Pona I, Hold A, Placheta E, Kropatsch WG, et al. Comparison of three-dimensional surface-imaging systems. $J$ Plast Reconstr Aesthet Surg. (2014) 67:489-97. doi: 10.1016/j.bjps.2014. 01.003

2. Papel ID, Jiannetto DF. Advances in computer imaging/applications in facial plastic surgery. Facial Plast Surg. (1999) 15:11925. doi: 10.1055/s-2008-1064308

3. Tzou $\mathrm{CH}$, Frey M. Evolution of 3D surface imaging systems in facial plastic surgery. Facial Plast Surg Clin North Am. (2011) 19:591-602. doi: 10.1016/j.fsc.2011.07.003

4. Doi K. Computer-aided diagnosis in medical imaging: historical review, current status and future potential. Comput Med Imag Graph. (2007) 31:198211. doi: 10.1016/j.compmedimag.2007.02.002

5. Weissler JM, Stern CS, Schreiber JE, Amirlak B, Tepper OM. The evolution of photography and three-dimensional imaging in plastic surgery. Plast Reconstr Surg. (2017) 139:761-9. doi: 10.1097/PRS.00000000000 03146

6. Chuang J, Barnes $\mathrm{C}$, Wong BJF. Overview of facial plastic surgery and current developments. Surg J. (2016) 2:e17-28. doi: 10.1055/s-0036-1572360

7. Soga S, Pomahac B, Mitsouras D, Kumamaru K, Powers SL, Prior RF, et al. Preoperative vascular mapping for facial allotransplantation: four-dimensional computed tomographic angiography versus magnetic resonance angiography. Plast Reconstr Surg. (2011) 128:883-91. doi: 10.1097/PRS.0b013e31822 $68 \mathrm{~b} 43$

8. Furukawa M, Mathes DW, Anzai Y. Evaluation of the facial artery on computed tomographic angiography using 64-slice multidetector computed tomography: implications for facial reconstruction in plastic surgery.
The future of the technology is still unclear as it will rely on certain surgical technological milestones to be met (quicker image processing techniques and smaller devices) alongside user preferences. However, there is an ultimate patient benefit to being able to pre-plan procedures in both outcomes and time. There are still costs related to this and these techniques may be difficult to integrate into developing countries and centers without the equipment or user ability on site.

\section{DATA AVAILABILITY STATEMENT}

The datasets generated for this study are available on request to the corresponding author.

\section{AUTHOR CONTRIBUTIONS}

ST: wrote majority and put paper together. MS: wrote parts of discussion and majority of introduction. RA: data extraction. ZJ and TD: data analysis and draft work. IW: oversaw project and draft work. All authors contributed to the article and approved the submitted version.

\section{FUNDING}

Medical Research Council (Grant Number: MR/N002431/1).
Plast Reconstr Surg. (2013) 131:526-35. doi: 10.1097/PRS.0b013e31827 c6f 18

9. Stella F, Dolci G, Dell'Amore A, Badiali G, De Matteis M, Asadi N, et al. Three-dimensional surgical simulation-guided navigation in thoracic surgery: a new approach to improve results in chest wall resection and reconstruction for malignant diseases. Interact Cardiovasc Thorac Surg. (2014) 18:7-12. doi: 10.1093/icvts/ivt440

10. Pratt R, Deprest J, Vercauteren T, Ourselin S, David AL. Computerassisted surgical planning and intraoperative guidance in fetal surgery: a systematic review. Prenat Diagn. (2015) 35:1159-66. doi: 10.1002/pd. 4660

11. Paterick TE, Patel N, Tajik AJ, Chandrasekaran K. Improving health outcomes through patient education and partnerships with patients. Proc. (Bayl Univ Med Cent). (2017) 30:112-3. doi: 10.1080/08998280.2017.119 29552

12. Moher D, Shamseer L, Clarke M, Ghersi D, Liberati A, Petticrew M, et al. Preferred reporting items for systematic review and meta-analysis protocols (PRISMA-P) 2015 statement. Syst Rev. (2015) 4:1. doi: 10.1186/2046-4 053-4-1

13. Yeung J-YS, Tarassoli S, Manivannan S, Dobbs T, Whitaker I. Current Image Acquisition and Processing Techniques for Facial Reconstruction: A Systematic Review (2018). Available from: https://www.crd.york.ac.uk/prospero/display_ record.php?ID=CRD42018105064 (accessed February 15, 2020).

14. Page MJ, McKenzie JE, Higgins JPT. Tools for assessing risk of reporting biases in studies and syntheses of studies: a systematic review. BMJ Open. (2018) 8:e019703. doi: 10.1136/bmjopen-2017-0 19703

15. Jørgensen L, Paludan-Müller AS, Laursen DRT, Savović J, Boutron I, Sterne JAC, et al. Evaluation of the Cochrane tool for assessing risk of bias in randomized clinical trials: overview of published comments and analysis 
of user practice in Cochrane and non-Cochrane reviews. Syst Rev. (2016) 5:80. doi: 10.1186/s13643-016-0259-8

16. Bilandzic A, Fitzpatrick T, Rosella L, Henry D. Risk of bias in systematic reviews of non-randomized studies of adverse cardiovascular effects of thiazolidinediones and cyclooxygenase-2 inhibitors: application of a new cochrane risk of bias tool. PLoS Med. (2016) 13:e1001987. doi: 10.1371/journal.pmed.1001987

17. Heissler E, Fischer FS, Bolouri S, Lehmann T, Mathar W, Gebhardt A, et al. Custom-made cast titanium implants produced with CAD/CAM for the reconstruction of cranium defects. Int J Oral Maxillofac Surg. (1998) 27:334-8. doi: 10.1016/S0901-5027(98)80060-X

18. Zamora N, Llamas JM, Cibrian R, Gandia JL, Paredes V. Cephalometric measurements from 3D reconstructed images compared with conventional 2D images. Angle Orthod. (2011) 81:856-64. doi: 10.2319/121210-717.1

19. Zamora N, Cibrián R, Gandia J-L, Paredes V. A new 3D method for measuring cranio-facial relationships with cone beam computed tomography. (CBCT). Med Oral Patol Oral Cir Bucal. (2013) 18:e70613. doi: $10.4317 /$ medoral.18671

20. Tenhagen M, Bruse JL, Rodriguez-Florez N, Angullia F, Borghi A, Koudstaal MJ, et al. Three-dimensional handheld scanning to quantify head-shape changes in spring-assisted surgery for sagittal craniosynostosis. J Craniofac Surg. (2016) 27:2117-23. doi: 10.1097/SCS.0000000000003108

21. Guo SS, Zhou WN, Wan LZ, Yuan H, Yuan Y, Du YF, et al. Computeraided design-based preoperative planning of screw osteosynthesis for type B condylar head fractures: a preliminary study. J Craniomaxillofac Surg. (2016) 44:167-76. doi: 10.1016/j.jcms.2015.11.013

22. Broumand SR, Labs JD, Novelline RA, Markowitz BL, Yaremchuk MJ. The role of three-dimensional computed tomography in the evaluation of acute craniofacial trauma. Ann Plast Surg. (1993) 31:488-94. doi: 10.1097/00000637-199312000-00002

23. Tello R, Suojanen J, Costello P, McGinnes A. Comparison of spiral CT and conventional CT in 3D visualization of facial trauma: work in progress. Comput Med Imaging Graph. (1994) 18:423-7. doi: 10.1016/0895-6111(94)90079-5

24. Eppley BL. Craniofacial reconstruction with computer-generated HTR patient-matched implants: use in primary bony tumor excision. J Craniofac Surg. (2002) 13:650-7. doi: 10.1097/00001665-200209000-00011

25. Klenk G, Kovacs A. Do we need three-dimensional computed tomography in maxillofacial surgery? J Craniofac Surg. (2004) 15:842-50; discussion 50. doi: 10.1097/00001665-200409000-00026

26. Rabie A, Ibrahim AM, Lee BT, Lin SJ. Use of intraoperative computed tomography in complex facial fracture reduction and fixation. J Craniofac Surg. (2011) 22:1466-7. doi: 10.1097/SCS.0b013e31821d1982

27. Gui H, Zhang S, Shen SG, Wang X, Bautista JS, Voss PJ. Real-time image-guided recontouring in the management of craniofacial fibrous dysplasia. Oral Surg Oral Med Oral Pathol Oral Radiol. (2013) 116:6805. doi: 10.1016/j.oooo.2013.07.012

28. Gerbino G, Bianchi FA, Zavattero E, Tartara F, Garbossa D, Ducati A. Single-step resection and reconstruction using patient-specific implants in the treatment of benign cranio-orbital tumors. J Oral Maxillofac Surg. (2013) 71:1969-82. doi: 10.1016/j.joms.2013.03.021

29. Schmutz B, Rahmel B, McNamara Z, Coulthard A, Schuetz M, Lynham A. Magnetic resonance imaging: an accurate, radiation-free, alternative to computed tomography for the primary imaging and three-dimensional reconstruction of the bony orbit. J Oral Maxillofac Surg. (2014) 72:6118. doi: 10.1016/j.joms.2013.08.030

30. Zhang L, Shen S, Yu H, Shen SG, Wang X. Computer-aided design and computer-aided manufacturing hydroxyapatite/epoxide acrylate maleic compound construction for craniomaxillofacial bone defects. J Craniofac Surg. (2015) 26:1477-81. doi: 10.1097/SCS.0000000000001410

31. Andrews BT, Thurston TE, Tanna N, Broer PN, Levine JP, Kumar A, et al. A multicenter experience with image-guided surgical navigation: broadening clinical indications in complex craniomaxillofacial surgery. J Craniofac Surg. (2015) 26:1136-9. doi: 10.1097/SCS.0000000000001672

32. Suzuki-Okamura E, Higashihori N, Kawamoto T, Moriyama K. Threedimensional analysis of hard and soft tissue changes in patients with facial asymmetry undergoing 2-jaw surgery. Oral Surg Oral Med Oral Pathol Oral Radiol. (2015) 120:299-306. doi: 10.1016/j.oooo.2015.05.020
33. Liu TJ, Ko AT, Tang YB, Lai HS, Chien HF, Hsieh TM. Clinical application of different surgical navigation systems in complex craniomaxillofacial surgery: the use of multisurface 3-dimensional images and a 2-plane reference system. Ann Plast Surg. (2016) 76:411-9. doi: 10.1097/SAP.0000000000000429

34. Tarsitano A, Battaglia S, Ramieri V, Cascone P, Ciocca L, Scotti R, et al. Shortterm outcomes of mandibular reconstruction in oncological patients using a CAD/CAM prosthesis including a condyle supporting a fibular free flap. $J$ Craniomaxillofac Surg. (2017) 45:330-7. doi: 10.1016/j.jcms.2016.12.006

35. El-Fiky I, El Sammak DAEA, El Sammak A, Abdelhady M. Diagnostic performance of multi-slice computed tomography using $2 \mathrm{D}$ and 3D images in the assessment of Le Fort fractures. Egypt J Radiol Nucl Med. (2017) 48:415-24. doi: 10.1016/j.ejrnm.2017.02.004

36. Tel A, Costa F, Sembronio S, Lazzarotto A, Robiony M. All-in-one surgical guide: a new method for cranial vault resection and reconstruction. J Cranio Maxillofac Surg. (2018) 46:967-73. doi: 10.1016/j.jcms.2018.03.020

37. Thiele OC, Nolte IM, Mischkowski RA, Safi AF, Perrin J, Zinser M, et al. Craniomaxillofacial patient-specific CAD/CAM implants based on conebeam tomography data - A feasibility study. J Craniomaxillofac Surg. (2018) 46:1461-4. doi: 10.1016/j.jcms.2018.05.056

38. Schimming R, Juengling FD, Lauer G, Schmelzeisen R. Evaluation of microvascular bone graft reconstruction of the head and neck with 3-D 99mTc-DPD SPECT scans. Oral Surg Oral Med Oral Pathol Oral Radiol Endod. (2000) 90:679-85. doi: 10.1067/moe.2000.111026

39. Schimming R, Juengling FD, Lauer G, Altehofer C, Schmelzeisen R. Computer-aided 3-D 99mTc-DPD-SPECT reconstruction to assess mandibular invasion by intraoral squamous cell carcinoma: diagnostic improvement or not? J Craniomaxillofac Surg. (2000) 28:325-30. doi: $10.1054 / \mathrm{jcms} .2000 .0171$

40. Suzuki A, Togawa T, Kuyama J, Nakahara T, Kinoshita F, Takenouchi T, et al. Evaluation of mandibular invasion by head and neck cancers using $99 \mathrm{mTc}-$ methylene diphosphonate or 99mTc-hydroxymethylene diphosphonate and $201 \mathrm{Tl}$ chloride dual isotope single photon emission computed tomography. Ann Nucl Med. (2004) 18:399-408. doi: 10.1007/BF02984483

41. Zhou LB, Shang HT, He LS, Bo B, Liu GC, Liu YP, et al. Accurate reconstruction of discontinuous mandible using a reverse engineering/computer-aided design/rapid prototyping technique: a preliminary clinical study. J Oral Maxillofac Surg. (2010) 68:2115-21. doi: 10.1016/j.joms.2009.09.033

42. Wang WH, Zhu J, Deng JY, Xia B, Xu B. Three-dimensional virtual technology in reconstruction of mandibular defect including condyle using doublebarrel vascularized fibula flap. J Craniomaxillofac Surg. (2013) 41:41722. doi: $10.1016 /$ j.jcms.2012.11.008

43. Xi T, Schreurs R, Heerink WJ, Berge SJ, Maal TJ. A novel region-growing based semi-automatic segmentation protocol for three-dimensional condylar reconstruction using cone beam computed tomography. (CBCT). PLoS ONE. (2014) 9:e111126. doi: 10.1371/journal.pone.0111126

44. Ayoub N, Ghassemi A, Rana M, Gerressen M, Riediger D, Holzle F, et al. Evaluation of computer-assisted mandibular reconstruction with vascularized iliac crest bone graft compared to conventional surgery: a randomized prospective clinical trial. Trials. (2014) 15:114. doi: 10.1186/1745-6215-15-114

45. Yu HB, Li B, Zhang L, Shen SG, Wang XD. Computer-assisted surgical planning and intraoperative navigation in the treatment of condylar osteochondroma. Int J Oral Maxillofac Surg. (2015) 44:113-8. doi: 10.1016/j.ijom.2014.08.009

46. Shan XF, Chen HM, Liang J, Huang JW, Zhang L, Cai ZG, et al. Surgical navigation-assisted mandibular reconstruction with fibula flaps. Int J Oral Maxillofac Surg. (2016) 45:448-53. doi: 10.1016/j.ijom.2015. 08.1006

47. Wu J, Sun J, Shen SG, Xu B, Li J, Zhang S. Computer-assisted navigation: its role in intraoperatively accurate mandibular reconstruction. Oral Surg Oral Med Oral Pathol Oral Radiol. (2016) 122:134-42. doi: 10.1016/j.oooo.2016.02.001

48. Wang YY, Zhang HQ, Fan S, Zhang DM, Huang ZQ, Chen WL, et al. Mandibular reconstruction with the vascularized fibula flap: comparison of virtual planning surgery and conventional surgery. Int J Oral Maxillofac Surg. (2016) 45:1400-5. doi: 10.1016/j.ijom.2016.06.015

49. Weijs WL, Coppen C, Schreurs R, Vreeken RD, Verhulst AC, Merkx $\mathrm{MA}$, et al. Accuracy of virtually $3 \mathrm{D}$ planned resection templates in 
mandibular reconstruction. J Craniomaxillofac Surg. (2016) 44:182832. doi: 10.1016/j.jcms.2016.08.024

50. Yu Y, Zhang WB, Liu XJ, Guo CB, Yu GY, Peng X. Three-dimensional accuracy of virtual planning and surgical navigation for mandibular reconstruction with free fibula flap. J Oral Maxillofac Surg. (2016) 74:1503.e1.e10. doi: 10.1016/j.joms.2016.02.020

51. Fu X, Qiao J, Girod S, Niu F, Liu JF, Lee GK, et al. Standardized protocol for virtual surgical plan and 3-dimensional surgical templateassisted single-stage mandible contour surgery. Ann Plast Surg. (2017) 79:23642. doi: 10.1097/SAP.0000000000001149

52. Mascha F, Winter K, Pietzka S, Heufelder M, Schramm A, Wilde F, Accuracy of computer-assisted mandibular reconstructions using patientspecific implants in combination with CAD/CAM fabricated transfer keys. $J$ Craniomaxillofac Surg. (2017) 45:1884-97. doi: 10.1016/j.jcms.2017.08.028

53. Sawh-Martinez R, Parsaei Y, Wu R, Lin A, Metzler P, DeSesa C, et al. Improved temporomandibular joint position after 3-dimensional planned mandibular reconstruction. J Oral Maxillofac Surg. (2017) 75:197206. doi: 10.1016/j.joms.2016.07.032

54. Kraeima J, Dorgelo B, Gulbitti HA, Steenbakkers R, Schepman KP, Roodenburg JLN, et al. Multi-modality 3D mandibular resection planning in head and neck cancer using CT and MRI data fusion: a clinical series. Oral Oncol. (2018) 81:22-8. doi: 10.1016/j.oraloncology.2018.03.013

55. Davies JC, Chan HHL, Jozaghi Y, Goldstein DP, Irish JC. Analysis of simulated mandibular reconstruction using a segmental mirroring technique. J Craniomaxillofac Surg. (2019) 47:468-72. doi: 10.1016/j.jcms.2018.12.016

56. Zhang M, Rao P, Xia D, Sun L, Cai X, Xiao J. Functional reconstruction of mandibular segment defects with individual preformed reconstruction plate and computed tomographic angiography-aided iliac crest flap. J Oral Maxillofac Surg. (2019) 77:1293-304. doi: 10.1016/j.joms.2019.01.017

57. Reiser V, Alterman M, Shuster A, Kleinman S, Shlomi B, Yanko-Arzi R, et al. V-stand-a versatile surgical platform for oromandibular reconstruction using a 3-dimensional virtual modeling system. J Oral Maxillofac Surg. (2015) 73:1211-26. doi: 10.1016/j.joms.2014.12.033

58. Ohkawa M, Tanabe M, Toyama Y, Kimura N, Uematsu K, Satoh G. The role of three-dimensional computed tomography in the management of maxillofacial bone fractures. Acta Med Okayama. (1997) 51:219-25.

59. Tao X, Yin X, Zhu F, Chen W. The clinical application of computerized threedimensional mimic operation for maxillofacial bone tumor. J Tongji Med Univ. (1999) 19:328-30. doi: 10.1007/BF02886975

60. Shaye DA, Tollefson TT, Strong EB. Use of intraoperative computed tomography for maxillofacial reconstructive surgery. JAMA Facial Plast Surg. (2015) 17:113-9. doi: 10.1001/jamafacial.2014.1343

61. Tarsitano A, Battaglia S, Ciocca L, Scotti R, Cipriani R, Marchetti C. Surgical reconstruction of maxillary defects using a computerassisted design/computer-assisted manufacturing-produced titanium mesh supporting a free flap. J Craniomaxillofac Surg. (2016) 44:1320-6. doi: 10.1016/j.jcms.2016.07.013

62. Zheng GS, Wang L, Su YX, Liao GQ, Zhang SE, Lao XM. Maxillary reconstruction assisted by preoperative planning and accurate surgical templates. Oral Surg Oral Med Oral Pathol Oral Radiol. (2016) 121:2338. doi: 10.1016/j.oooo.2015.10.010

63. Frellesen C, Wichmann JL, Tischendorf P, Scholtz JE, Beeres M, Vogl TJ, et al. High-pitch dual-source paranasal sinus CT in agitated patients with maxillofacial trauma: analysis of image quality, motion artifacts, and dose aspects. Acta Radiol. (2018) 59:909-16. doi: 10.1177/02841851177 40931

64. Kwon J, Barrera JE, Jung TY, Most SP. Measurements of orbital volume change using computed tomography in isolated orbital blowout fractures. Arch Facial Plast Surg. (2009) 11:395-8. doi: 10.1001/archfacial.20 09.77

65. Novelli G, Tonellini G, Mazzoleni F, Bozzetti A, Sozzi D. Virtual surgery simulation in orbital wall reconstruction: integration of surgical navigation and stereolithographic models. J Craniomaxillofac Surg. (2014) 42:202534. doi: 10.1016/j.jcms.2014.09.009

66. Tsao K, Cheng A, Goss A, Donovan D. The use of cone beam computed tomography in the postoperative assessment of orbital wall fracture reconstruction. J Craniofac Surg. (2014) 25:1150-4. doi: 10.1097/SCS.0000000000000747

67. Tabakovic SZ, Konstantinovic VS, Radosavljevic R, Movrin D, Hadzistevic M, Hatab N. Application of computer-aided designing and rapid prototyping technologies in reconstruction of blowout fractures of the orbital floor. $J$ Craniofac Surg. (2015) 26:1558-63. doi: 10.1097/SCS.0000000000001883

68. Tarsitano A, Badiali G, Pizzigallo A, Marchetti C. Orbital reconstruction: patient-specific orbital floor reconstruction using a mirroring technique and a customized titanium mesh. J Craniofac Surg. (2016) 27:18225. doi: 10.1097/SCS.0000000000002907

69. Gander T, Blumer M, Rostetter C, Wagner M, Zweifel D, Schumann P, et al. Intraoperative 3-dimensional cone beam computed tomographic imaging during reconstruction of the zygoma and orbit. Oral Surg Oral Med Oral Pathol Oral Radiol. (2018) 126:192-7. doi: 10.1016/j.oooo.2018.04.008

70. Gibelli D, Cellina M, Gibelli S, Oliva AG, Termine G, Pucciarelli V, et al. Assessing symmetry of zygomatic bone through three-dimensional segmentation on computed tomography scan and "mirroring" procedure: A contribution for reconstructive maxillofacial surgery. J Craniomaxillofac Surg. (2018) 46:600-4. doi: 10.1016/j.jcms.2018.02.012

71. Sozzi D, Gibelli D, Canzi G, Tagliaferri A, Monticelli L, Cappella A, et al. Assessing the precision of posttraumatic orbital reconstruction through "mirror" orbital superimposition: a novel approach for testing the anatomical accuracy. J Craniomaxillofac Surg. (2018) 46:1258-62. doi: 10.1016/j.jcms.2018.05.040

72. Kim H, Son T-G, Lee J, Kim HA, Cho H, Jeong WS, et al. Three-dimensional orbital wall modeling using paranasal sinus segmentation. J Cranio Maxillofac Surg. (2019) 47:959-67. doi: 10.1016/j.jcms.2019.03.028

73. Dong QN, Karino M, Koike T, Ide T, Okuma S, Kaneko I, et al. Navigationassisted isolated medial orbital wall fracture reconstruction using an $\mathrm{U}$ HA/PLLA sheet via a transcaruncular approach. J Invest Surg. (2020) 33:64452. doi: 10.1080/08941939.2018.1546353

74. Heiland M, Schulze D, Blake F, Schmelzle R. Intraoperative imaging of zygomaticomaxillary complex fractures using a 3D C-arm system. Int J Oral Maxillofac Surg. (2005) 34:369-75. doi: 10.1016/j.ijom.2004.09.010

75. Fan $\mathrm{X}$, Zhou H, Lin M, Fu Y, Li J. Late reconstruction of the complex orbital fractures with computer-aided design and computer-aided manufacturing technique. J Craniofac Surg. (2007) 18:665-73. doi: 10.1097/scs.0b013e31803ffaaa

76. Kolk A, Pautke C, Wiener E, Schott V, Wolff KD, Horch HH, et al. Isotropic proton-density-weighted high-resolution MRI for volume measurement of reconstructed orbital fractures-a comparison with multislice CT. Magn Reson Imaging. (2008) 26:1167-74. doi: 10.1016/j.mri.2008.01.017

77. Wang $\mathrm{X}$, Lin $\mathrm{Y}$, Yu $\mathrm{H}$, Cheng $\mathrm{AH}$, Sun $\mathrm{H}$, Wang $\mathrm{C}$, et al. Image-guided navigation in optimizing surgical management of craniomaxillofacial fibrous dysplasia. J Craniofac Surg. (2011) 22:1552-6. doi: 10.1097/SCS.0b013e31822e5d3d

78. Zhang S, Liu X, Xu Y, Yang C, Undt G, Chen M, et al. Application of rapid prototyping for temporomandibular joint reconstruction. J Oral Maxillofac Surg. (2011) 69:432-8. doi: 10.1016/j.joms.2010.05.081

79. Myga-Porosiło J, Skrzelewski S, Sraga W, Borowiak H, Jackowska Z, Kluczewska E. CT Imaging of facial trauma. Role of different types of reconstruction Part I - bones. Pol J Radiol. (2011) 76:41-51.

80. Lim JH, Jun BC, Song SW. Clinical feasibility of multiplanar reconstruction images of temporal bone CT in the diagnosis of temporal bone fracture with otic-capsule-sparing facial nerve paralysis. Indian J Otolaryngol Head Neck Surg. (2013) 65:219-24. doi: 10.1007/s12070-011-0471-8

81. Wilde F, Lorenz K, Ebner AK, Krauss O, Mascha F, Schramm A. Intraoperative imaging with a 3D C-arm system after zygomatico-orbital complex fracture reduction. J Oral Maxillofac Surg. (2013) 71:894910. doi: 10.1016/j.joms.2012.10.031

82. An G, Gui L, Liu J, Niu F, Chen Y, Wang M. Treatment of fibrous dysplasia orbital deformities with digital imaging guidance. J Craniofac Surg. (2015) 26:449-51. doi: 10.1097/SCS.0000000000001197

83. Shan XF, Chen HM, Liang J, Huang JW, Cai ZG. Surgical reconstruction of maxillary and mandibular defects using a printed titanium mesh. J Oral Maxillofac Surg. (2015) 73:1437.e1-9. doi: 10.1016/j.joms.2015.02.025

84. Farook AK, Ilangovan G, Ravi R, Farook AS, Magudeeswaran PK. Role of multiplanar reconstruction imaging and three-dimensional computed tomography imaging in diagnosing cranial and facial fractures. Int $J$ Sci Study. (2016) 4:237-41. doi: 10.17354/ijss/2016/224

85. Kokosis G, Davidson EH, Pedreira R, Macmillan A, Dorafshar AH. The use of computer-aided design and manufacturing in acute mandibular trauma reconstruction. J Oral Maxillofac Surg. (2018) 76:1036-43. doi: 10.1016/j.joms.2017.12.008 
86. Guest W, Forbes D, Schlosser C, Yip S, Coope R, Chew J. Imaging-based 3-dimensional printing for improved maxillofacial presurgical planning: a single center case series. Can Assoc Radiol J. (2019) 70:74-82. doi: 10.1016/j.carj.2018. 10.002

87. Lin $\mathrm{HH}$, Lonic $\mathrm{D}$, Lo LJ. $3 \mathrm{D}$ printing in orthognathic surgery - A literature review. J Formos Med Assoc. (2018) 117:54758. doi: 10.1016/j.jfma.2018.01.008

88. Coskun U, Ozturk S, Zor F, Turgut AT, Sengezer M. Imaging of porous polyethylene implant by using multidetector spiral computed tomography. $J$ Craniofac Surg. (2008) 19:156-8. doi: 10.1097/scs.0b013e31815c8a3a
Conflict of Interest: The authors declare that the research was conducted in the absence of any commercial or financial relationships that could be construed as a potential conflict of interest.

Copyright (c) 2020 Tarassoli, Shield, Allen, Jessop, Dobbs and Whitaker. This is an open-access article distributed under the terms of the Creative Commons Attribution License (CC BY). The use, distribution or reproduction in other forums is permitted, provided the original author(s) and the copyright owner(s) are credited and that the original publication in this journal is cited, in accordance with accepted academic practice. No use, distribution or reproduction is permitted which does not comply with these terms. 